\title{
A Study of the Differences in the Gas Diffusion and Migration Characteristics of Soft and Hard Coal in High Gas Coal Seams
}

\author{
Anying Yuan (iD) \\ State Key Laboratory of Mining Response and Disaster Prevention and Control in Deep Coal Mines, \\ Anhui University of Science and Technology, Huainan City, Anhui Province 232001, China \\ Correspondence should be addressed to Anying Yuan; ayyuan@aust.edu.cn
}

Received 14 March 2020; Revised 17 May 2020; Accepted 7 July 2020; Published 28 July 2020

Academic Editor: Bisheng Wu

Copyright (c) 2020 Anying Yuan. This is an open access article distributed under the Creative Commons Attribution License, which permits unrestricted use, distribution, and reproduction in any medium, provided the original work is properly cited.

At the present time, it is of major significance to examine the differences in the gas diffusion and migration characteristics of soft and hard coal in order to prevent and control safety hazards in high gas coal seams. In this study, the differences in the gas diffusion and migration characteristics between soft coal and hard coal were examined in detail using macrostructural, mesostructural, and microstructural research methods. The root causes of the differences in the gas diffusion and migration between soft coal and hard coal were revealed in the obtained research results. The study shows that, in terms of the macrostructures, the soft coal particle grains were flakey and with shapes resembling fingernails. Meanwhile, the hard coal particle grains were observed to be in the shapes of complete blocks. In addition, in terms of the mesostructures of the different coal types, it was found that the proportion of granular coal below the particle size limit of $6 \mathrm{~mm}$ in the soft coal was much higher than that of the hard coal. Also, from the aspect of the characteristics of the microstructures, the pores and fissures on the soft coal surfaces were observed to be better developed, and the $\mathrm{BJH}$ specific surface areas of the soft coal were more than twice those of the hard coal. That is to say, the gas diffusion and migration conditions of the soft coal were better than those of the hard coal. At the same time, the increments of the specific surface areas and volumes of the pores of soft coal were above $100 \mathrm{~nm}$, which provided channels for gas diffusion and migration at rates of more than twice those of the hard coal. Therefore, the soft coal was more conducive to gas emissions. This study conducted gas desorption experiments on both soft and hard coal samples and found that the initial gas desorption speed of the soft coal was significantly higher than that of the hard coal. Since the instantaneous gas emissions of the soft coal were significantly higher than those of the hard coal, it was considered to be more likely that gas outbursts and transfinite accidents could potentially occur in the soft coal layers of a project site. This study's results provided a foundation and basis for effective gas control measures in coal seams composed of soft coal layers, which will be of major significance to the safety of coal mining activities in the future.

\section{Introduction}

Gas emissions are a type of disastrous gas hazard which may potentially impact the safe production processes of coal mines [1]. Coal seams that contain high content levels of gas are known to be easily affected by gas outburst accidents resulting in casualties and property losses [2-4]. However, within the same coal seam, different types of coal bodies may display significant differences in gas emission amounts, which pose greater challenges for the prevention and control of gas emissions in mine working faces [5-7].
It was determined that several of the examined examples of coal and gas outbursts indicated that outburst accidents with prediction and effect inspection indexes not exceeding the standard limits had occurred in the soft layers of the coal seam, and the gas desorption laws of the soft and hard coal bodies were quite different [8-10]. It was observed that using the desorption laws of hard coal to test the gas content levels in soft coal seams, along with the gas desorption indexes of drill cuttings, would potentially lead to large errors in the test results.

Previously, many experts and scholars in the field have conducted in-depth research regarding the characteristics of 
gas diffusion and migration in coal seams [11-13]. Some researchers believe that the majority of coal and gas outburst accidents occur on the roadways of driving faces and at both ends of working faces. This is due to the fact that the aforementioned areas tend to be disturbed by mining activities, and a general phenomenon of stress concentration is present, which plays a leading role in gas outburst events [14-17]. Second, some researchers have theorized that coal deposits, as the main carrier of coal and gas outbursts, are the objects of the gas outbursts, and the mechanical characteristics, pore structure characteristics, and other factors of the coal bodies themselves play important roles in the gas emission processes [18-22].

Therefore, in view of the gas emission laws of coal bodies, experts in the field have adopted many research methods, including gas adsorption and desorption experiments, microscanning, micropore structure analyses, and mercury injection experiments [23-25]. However, the majority of the research studies generally utilize one or two of the aforementioned methods to examine the gas desorption laws of coal bodies. As a result, different research findings have been presented. In particular, there have been relatively few studies conducted regarding the phenomena observed in soft and hard coal bodies within the same coal seam.

In the present research, from the aspects of the macrostructures, mesostructures, and microstructures of soft coal and hard coal, gas desorption experiments were conducted in order to comprehensively analyze the root causes of the differences in the characteristics of gas diffusion and migration in soft coal and hard coal. The results of the experimental processes revealed the mechanism of the differences in the gas emissions of soft coal and hard coal, which provided a foundation and basis for the prevention and control of coal seam gas disasters under similar conditions, which was considered to be of major significance to future coal mining projects.

\section{Differences in the Characteristics of the Macrostructures and Mesostructures of Soft Coal and Hard Coal}

In order to examine the differences in the gas diffusion processes between the soft coal and hard coal in high gas coal seams, the characteristics of macrostructures and mesostructures of soft and hard coal samples were first analyzed. In this study, soft coal and hard coal samples obtained from the No. 6 and No. 11 high gas coal seams of the Xieqiao Coal Mine in China's Huainan mining area were selected. The No. 6 coal seam and No. 11 coal seam both contained soft layers (hereinafter referred to as the soft coal), and the physical and mechanical properties of soft layers and normal coal bodies (hereinafter referred to as the hard coal) were obviously different.

Figure 1 shows the macro characteristics of the soft coal and hard coal in each coal seam. It can be seen in the figure that the soft coal in each coal seam generally contained no large blocks, and the coal particles were generally uniform in size, displaying approximately nailshaped flakey particles. Meanwhile, the hard coal was mainly in the form of blocks.

An artificial crushing method was adopted in this study to simulate the crushing processes, which occur during the mining of a working face. A standard sieve was used to screen the soft coal and hard coal samples in order to obtain the fine particle size distribution law of the soft coal and hard coal, as shown in Figure 2. The results indicated that there was a particle size limit during the process in which the particle sizes influenced the desorption and diffusion of the coal particle gas. The limit of the particle size was considered to be the inherent particle size of the coal, which was related to the degree of damage and metamorphism of the coal, with a maximum size of no more than $6 \mathrm{~mm}$. It was observed that, in the ranges less than the particle size limit, the gas desorption strength and attenuation coefficient decreased with the increases in the coal particle sizes. However, when the coal particle sizes were larger than the particle size limit $(6 \mathrm{~mm})$, the decreasing trends of the gas desorption strength and attenuation coefficient with the increases in the coal particle sizes were not obvious. Therefore, this study selected a $6 \mathrm{~mm}$ particle size as the boundary for the purpose of analyzing the particle size distributions in the raw coal.

The results of this study's comparative analysis showed that the proportions of coal particles below $6 \mathrm{~mm}$ in the soft coal of the No. 6 and No. 11 coal seams were $54.63 \%$ and $68.54 \%$, respectively. The proportions of the coal particles below $6 \mathrm{~mm}$ in the hard coal of the No. 6 and No. 11 coal seams were determined to be $17.72 \%$ and $21.45 \%$, respectively. Therefore, the proportions of coal particles below $6 \mathrm{~mm}$ in soft coal were more than 3 times those of the hard coal. In other words, the proportions of coal particles below $6 \mathrm{~mm}$ in the soft coal of each examined coal seam were far higher than those of the hard coal.

\section{Differences in the Micropore Structures of the Soft Coal and Hard Coal}

In order to further explore the underlying mechanism of the differences in the gas diffusion and migration between the soft coal and hard coal, this study examined the micropore structures of each type of coal. A Micrometrics ASAP 2460 multistation specific surface and porosity analyzer was used for the determination of the micropore structural parameters, as shown in Figure 3.

3.1. Comparative Analysis of the Specific Surface Areas of the Soft Coal and Hard Coal. Figure 4 shows this study's comparative analysis diagram of the BET specific surface areas and $\mathrm{BJH}$ specific surface areas of the soft coal and hard coal in the different coal seams. Table 1 shows this study's pore structural parameters of the soft coal and hard coal in the different coal seams. It can be seen in Figure 4 and Table 1 that the BET specific surface areas of the soft coal and hard coal in the No. 6 coal seam were $3.5421 \mathrm{~m}^{2} / \mathrm{g}$ and $1.8008 \mathrm{~m}^{2} / \mathrm{g}$, respectively. That is to say, the BET specific surface area of soft coal in the No. 6 coal seam was 


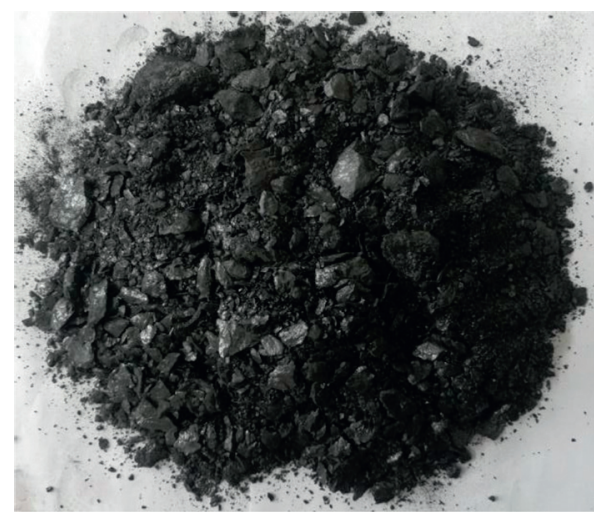

(a)

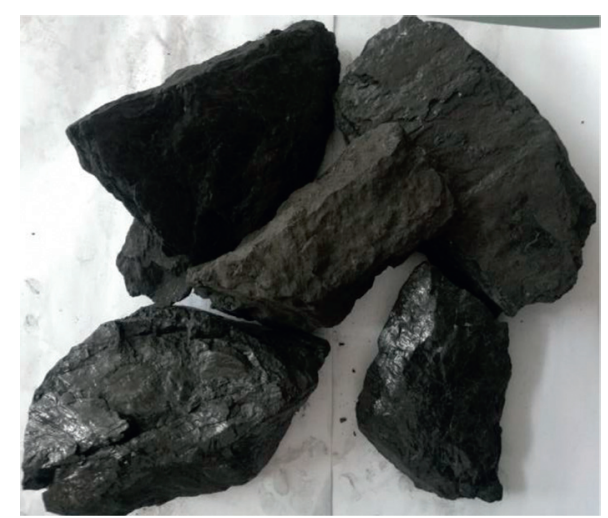

(b)

Figure 1: Macroscopic characteristics of soft coal and hard coal. (a) Soft coal. (b) Hard coal.

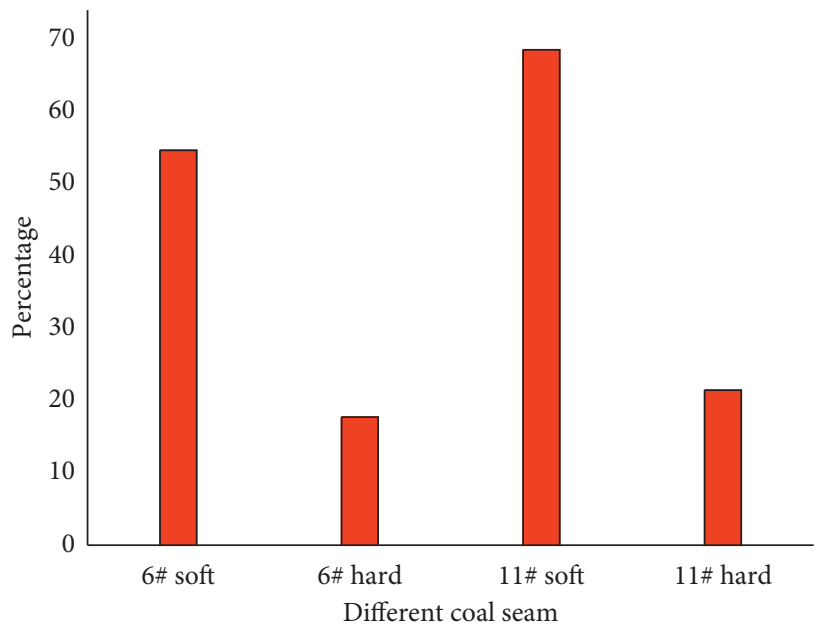

Figure 2: Percentages of soft coal and hard coal with particle sizes less than $6 \mathrm{~mm}$ in each coal seam.

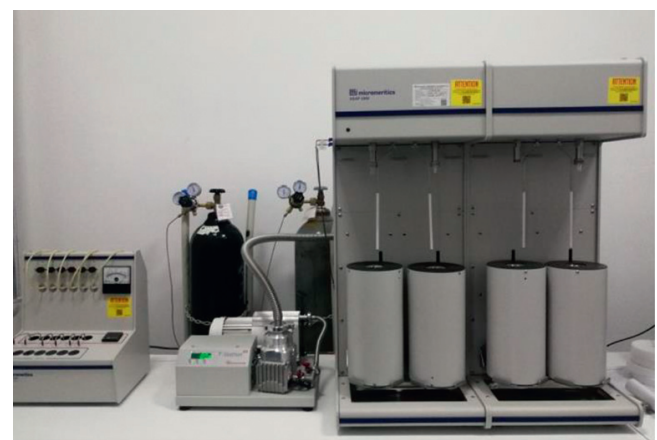

FIGURE 3: ASAP 2460 multistation specific surface and porosity analyzer.

approximately twice that of the hard coal, which indicated that the gas adsorption conditions of the soft coal in the No. 6 coal seam were superior to those of the hard coal. In addition, it was determined that the BET specific surface areas of the soft coal and hard coal in the No. 11 coal seam were $1.6179 \mathrm{~m}^{2} / \mathrm{g}$ and $0.8278 \mathrm{~m}^{2} / \mathrm{g}$, respectively. Therefore, the BET specific surface area of the soft coal in the No. 11 coal

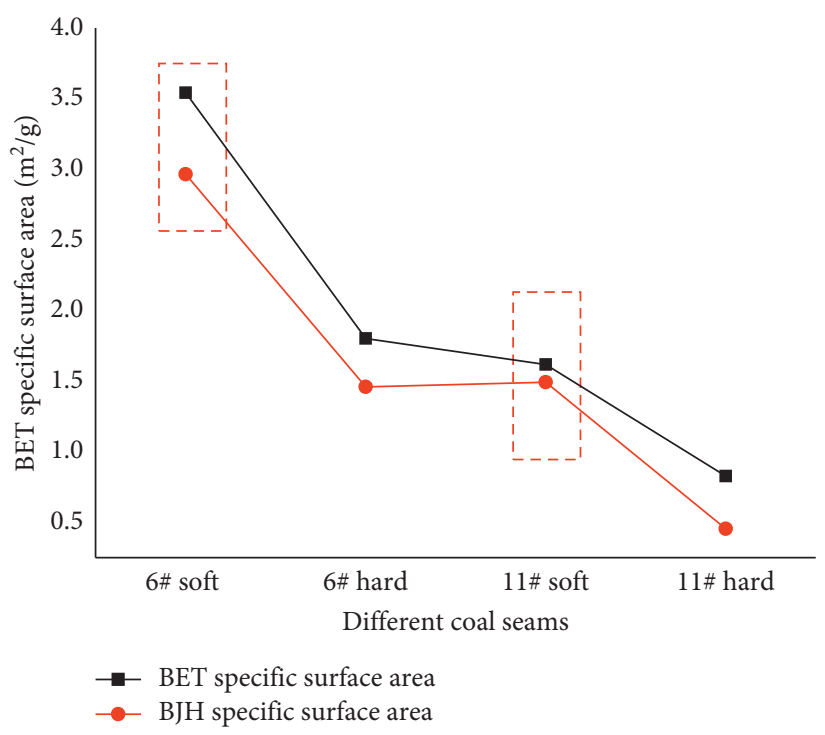

FIgURE 4: Specific surface areas of the coal bodies in the different coal seams.

seam was confirmed to be approximately twice that of the hard coal, indicating that the gas adsorption conditions of the soft coal in the No. 11 coal seam were also better than those of the hard coal. As detailed in Figure 3, the BJH specific surface areas of the soft coal and hard coal in the No. 6 coal seam were $2.9642 \mathrm{~m}^{2} / \mathrm{g}$ and $1.4593 \mathrm{~m}^{2} / \mathrm{g}$, respectively. Therefore, the BJH specific surface areas of the soft coal were more than twice those of the hard coal, which indicated that the gas diffusion and migration conditions of the soft coal in the No. 6 coal seam were superior. The BJH specific surface areas of the soft coal and hard coal of the No. 11 coal were $1.4921 \mathrm{~m}^{2} / \mathrm{g}$ and $0.453 \mathrm{~m}^{2} / \mathrm{g}$, respectively. Therefore, it was determined that the $\mathrm{BJH}$ specific surface areas of the soft coal were more than three times those of the hard coal, which indicated that the gas diffusion and migration conditions of the soft coal in the No. 11 coal seam were better than those of the hard coal within the same coal seam.

In conclusion, the BET specific surface areas and $\mathrm{BJH}$ specific surface areas of soft coal were found to be 
significantly larger than those of the hard coal. As a result, it was concluded that the conditions for gas adsorption and diffusion migration of the soft coal were stronger than those of the hard coal.

3.2. Relationships between the Pore Sizes, Specific Surface Areas, and Pore Volumes. Figures 5 and 6 show the relationships between the increments of the pore sizes and specific surface areas, as well as the relationships between the increments of pore sizes and pore volumes, of the soft coal and hard coal in the No. 6 coal seam, respectively. It can be seen in the aforementioned figures that the increments of the specific surface areas and pore volumes corresponding to the soft coal pore sizes above $100 \mathrm{~nm}$ were significantly larger than those of the hard coal. The maximum increment of the pore volumes corresponding to the pore sizes greater than $100 \mathrm{~nm}$ in the soft coal was $9 \times 10^{-5} \mathrm{~cm}^{3} / \mathrm{g}$. In addition, the maximum increment of the pore volume corresponding to the pore sizes above $100 \mathrm{~nm}$ in the hard coal was $3.5 \times 10^{-5} \mathrm{~cm}^{3} / \mathrm{g}$. Therefore, the increment of the soft coal was approximately 2.6 times that of the hard coal, as shown in the blue-dashed boxes in Figures 5(b) and 6(b).

Figures 7 and 8 show the relationships between the increments of the pore sizes and specific surface areas and the relationships between the increments of the pore sizes and pore volumes of the soft and hard coal in the No. 11 coal seam, respectively. It can be seen in the figure that the increments of the specific surface areas and pore volumes corresponding to the pore sizes greater than $100 \mathrm{~nm}$ in the soft coal were significantly larger than those of the hard coal, wherein the maximum increment of pore volume corresponding to the pore sizes greater than $100 \mathrm{~nm}$ in the soft coal was $12.5 \times 10^{-5} \mathrm{~cm}^{3} / \mathrm{g}$. The maximum increment of the pore volume corresponding to the pore sizes greater than $100 \mathrm{~nm}$ in the hard coal was determined to be $6.2 \times 10^{-5} \mathrm{~cm}^{3} / \mathrm{g}$. Therefore, the increment of the soft coal was approximately 2 times that of the hard coal, as indicated in the blue-dashed boxes in Figures 7(b) and $8(\mathrm{~b})$.

Based on the above analysis of the increments of the pore diameter and specific surface areas and the increments of the pore volumes of the soft coal and hard coal in the two examined coal seams, it was concluded that the pore specific surface area increments and the pore volume increments of the soft coal with apertures larger than $100 \mathrm{~nm}$ were more than twice those of the hard coal. These findings indicated that the soft coal provided better conditions for gas diffusion and migration. In other words, the soft coal was determined to be more conducive to gas desorption and diffusion.

3.3. Comparative Analysis Results of the Microscanning of the Soft Coal and Hard Coal. In the present study, a FlexSEM 1000 scanning electron microscope was used to conduct microscopic scanning of the soft coal and hard coal, respectively. The results are shown in Figure 9. It can be seen in the figure that the soft coal surfaces of the two coal seams were very rough and uneven, and the gas pores were relatively developed (as shown in Figures 9(a) and $9(c))$. The pore edges were mainly zig-zagged in appearance, with significant differences observed in the pore sizes. In addition, pores ranging from several microns to dozens of microns were developed. The most direct impact of these relatively developed pores in the high gas coal seam was the corresponding increases in the gas adsorption capacity. There were many crush marks and stepped fracture scale structures were also observed. These structures had greatly increased the surface areas of the coal bodies, which had contacts outside the coal seams. At the same time, the crush marks formed under the action of the structural compressive stress had led to the obvious development of microcracks, as well as good connectivity between the pores. This had resulted in the formations of dominant channels for gas flow. In contrast, the surfaces of the hard coal were found to be more complete, with the characteristics of thin-layer shear fractures, thin sections, and crumpled deformations. In addition, local roughness and unevenness, scattered minerals, and coal chips on the surfaces were observed, with few pores in local areas and no obvious cracks. Therefore, based on the above analysis results, it was concluded that the development of pores and fractures in the soft coal had provided "good" conditions for gas adsorption and desorption, respectively. Therefore, more attention should be paid to the gas emissions of soft coal during coal mining processes.

3.4. Differences in the Gas Desorption and Diffusion Laws of the Soft Coal and Hard Coal. Figure 10 shows the gas desorption speeds of the soft coal and hard coal and the change laws of the gas desorption amounts with time. It can be seen in Figure 10(a) that the gas desorption speeds of the soft coal and hard coal continuously decreased with the increases of time. During the initial stage of the desorption, the gas desorption speeds had decreased violently. Then, with the increases in duration, the gas desorption speeds slowly decreased. It can be seen from the curve in the red-dotted line box of Figure 10(a) and the data in Table 2 that the initial gas desorption speed of the soft coal was significantly higher than that of the hard coal. Due to the fact that the initial gas desorption speed represents the initial instantaneous gas emission in a coal body, the instantaneous gas emission of the soft coal was found to be significantly higher than that of the hard coal. Therefore, it was considered to be more likely to cause gas outbursts and transfinite accidents in the project site. It was ascertained from the data shown in Figure 10(b) and Table 2 that the gas desorption capacities of the soft coal and hard coal in each coal seam had gradually increased with time. However, the increasing trend had gradually slowed down. It was observed that the gas desorption capacity of the soft coal was also significantly higher than that of the hard coal, and the gas desorption speed and gas desorption capacity of the No. 6 coal seam were higher than those of the No. 11 coal seam. 
TABLE 1: Pore structural parameters of the soft coal and hard coal in the different coal seams.

\begin{tabular}{lllll}
\hline Pore structural parameters $\left(\mathrm{m}^{2} / \mathrm{g}\right)$ & \multicolumn{4}{c}{ Soft coal and hard coal bodies of the different coal seams } \\
& No. 6 soft & No. 6 hard & No. 11 soft & No. 11 hard \\
\hline BET specific surface areas & 3.5421 & 1.8008 & 1.6179 & 0.8278 \\
BJH specific surface areas & 2.9642 & 1.4593 & 1.4921 & 0.453 \\
\hline
\end{tabular}

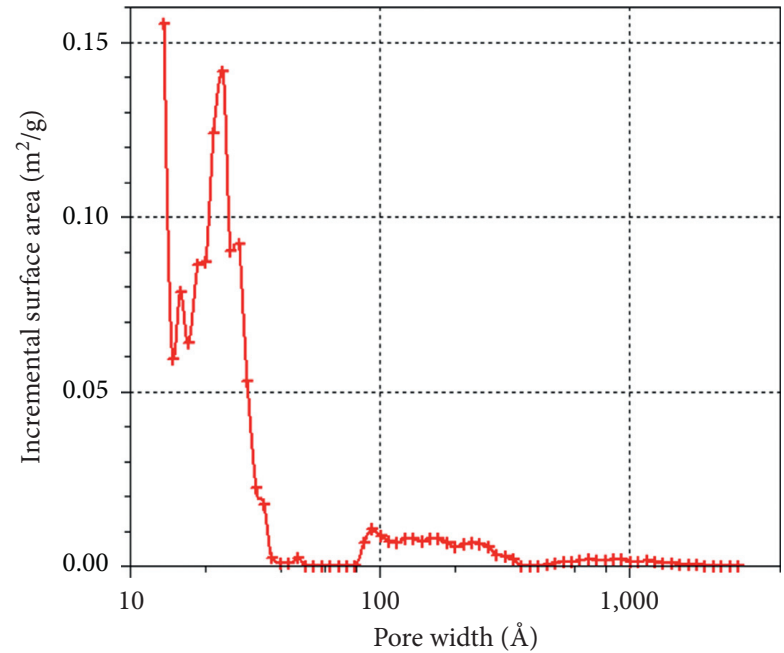

(a)

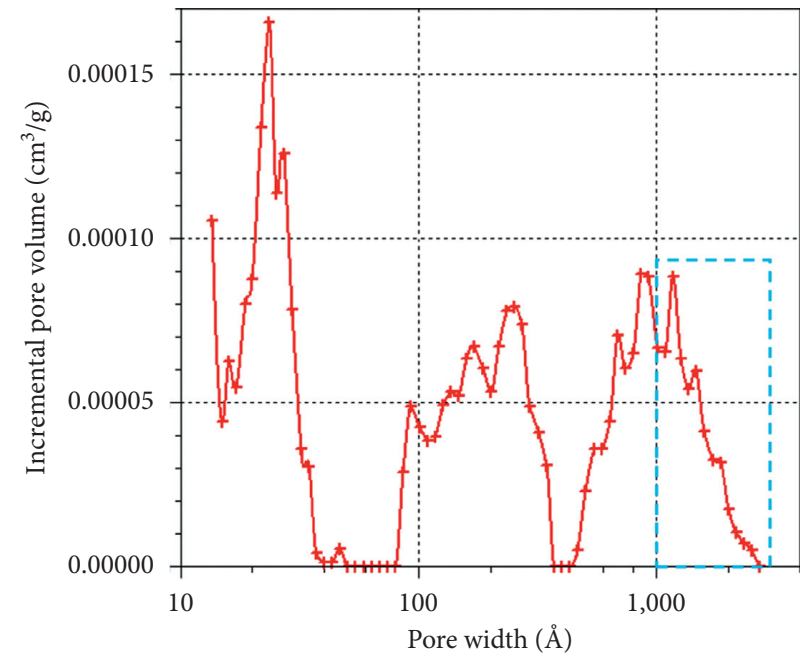

(b)

FIGURE 5: Diagram of the relationships between the increments of the pore sizes and the specific surface areas and the increments of the pore volumes of the soft coal of the No. 6 coal seam. (a) Relationships between the increments of the pore sizes and the specific surface areas. (b) Relationship between the increments of the pore sizes and the pore volumes; A is $10^{-1} \mathrm{~nm}$.

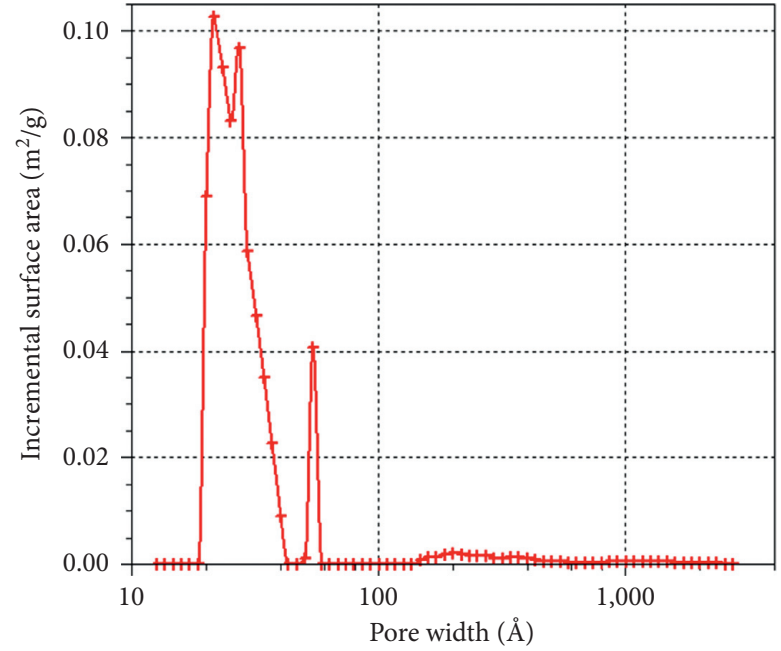

(a)

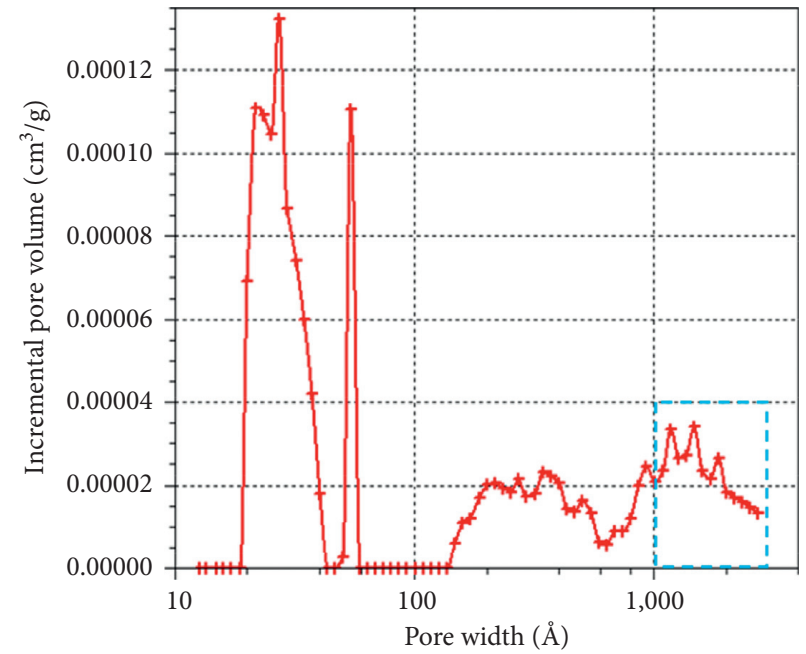

(b)

FIGURE 6: Diagram of the relationships between the increments of the pore sizes and the specific surface areas and the increments of the pore volumes of the hard coal in the No. 6 coal seam. (a) Relationships between the increments of the pore sizes and the specific surface areas. (b) Relationships between the increments of the pore sizes and the pore volumes; A is $10^{-1} \mathrm{~nm}$. 


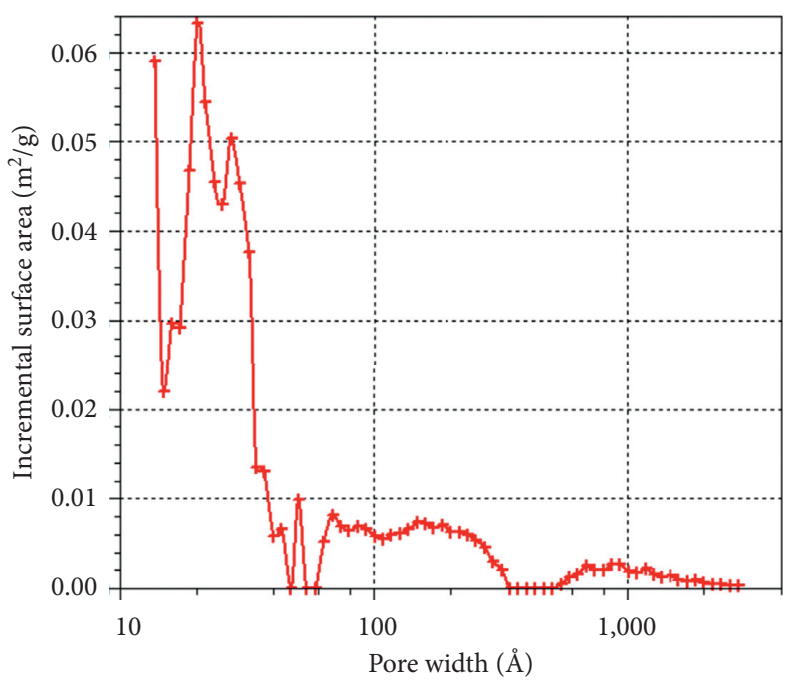

(a)

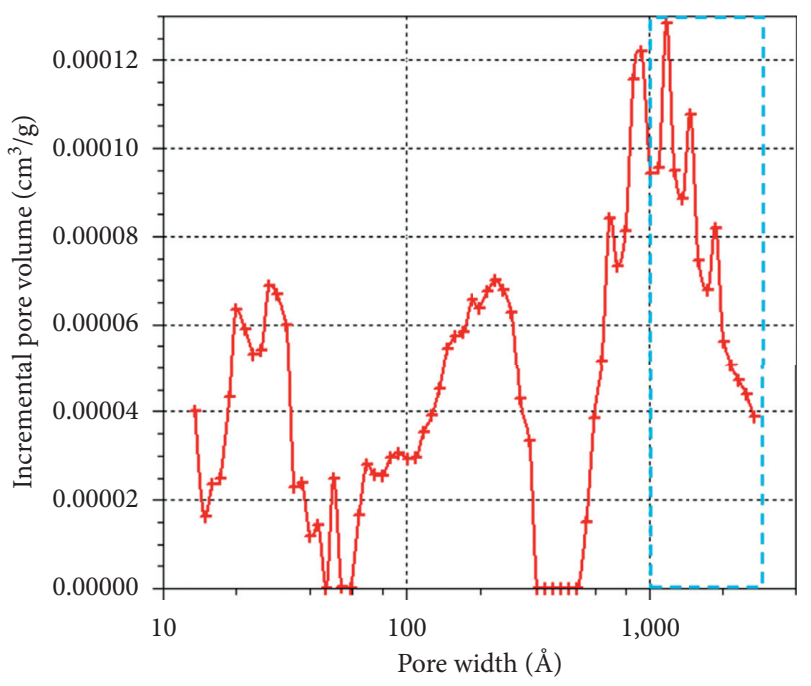

(b)

FiguRE 7: Diagram of the relationships between the increments of the pore sizes and the specific surface areas and the increments of pore volumes of the hard coal of the No. 11 coal seam. (a) Relationships between the increments of the pore sizes and the specific surface areas. (b) Relationships between the increments of the pore sizes and the pore volumes; (A) is $10^{-1} \mathrm{~nm}$.

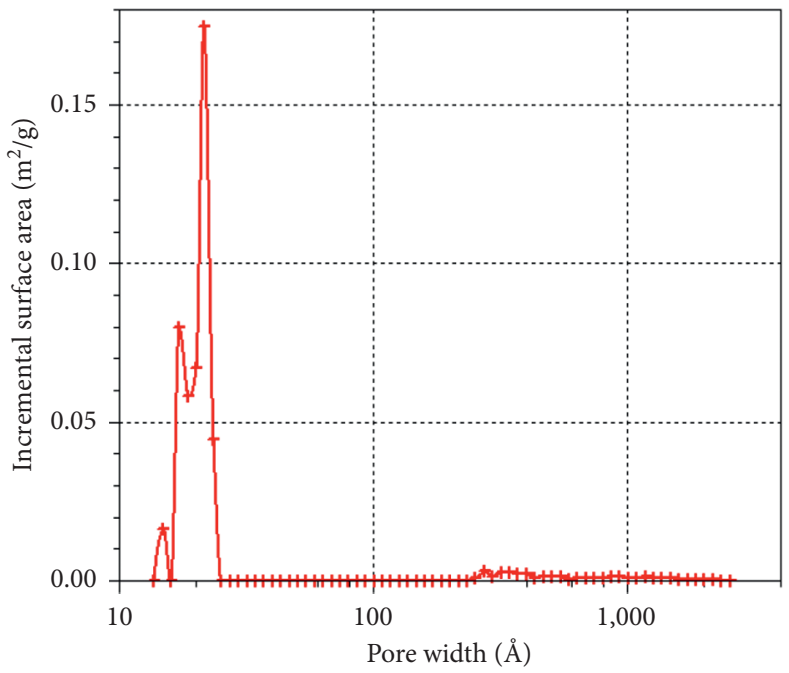

(a)

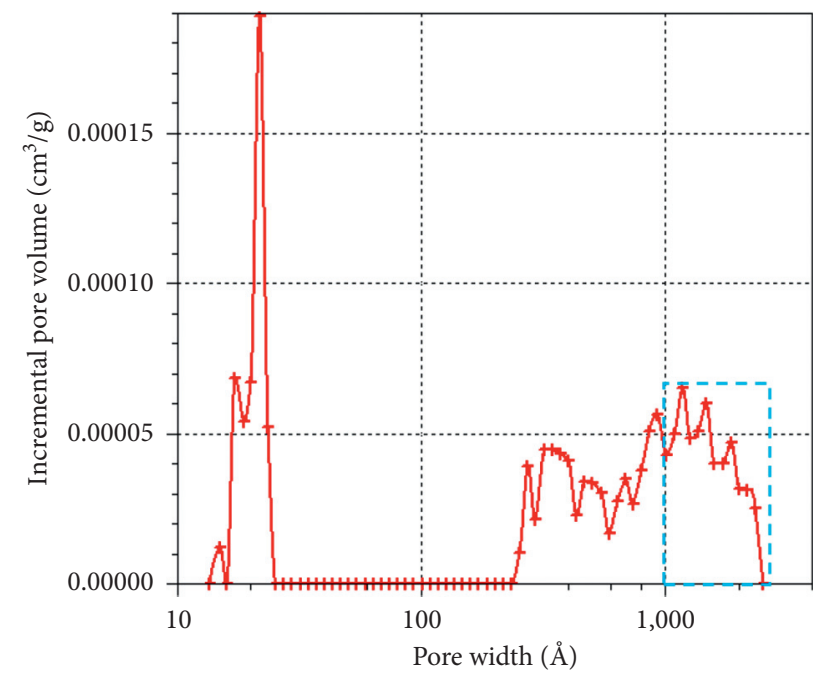

(b)

FIGURE 8: Diagram of the relationships between the increments of the pore sizes and the specific surface areas and the increments of the pore volumes of the hard coal of the No. 11 coal seam. (a) Relationships between the increments of the pore sizes and the specific surface areas. (b) Relationships between the increments of the pore sizes and the pore volumes; (A) is $10^{-1} \mathrm{~nm}$.

\section{Differential Mechanism Analysis of the Gas Diffusion and Migration Processes in the Soft Coal and Hard Coal}

In accordance with the pore classification method, micropores and pores provide the majority of the specific surface areas in pore structures and are the main sites for gas adsorption and storage. The BET specific surface areas of the soft coal and hard coal were found to be quite different, which indicated that the gas adsorption capacities of the soft coal and hard coal were also different. The increments of the specific surface areas and pore volumes of the mesopores and large pores of the soft coal were found to be much larger than those of the hard coal. In addition, since the mesopores and large pores were the main paths and channels for gas desorption in the micropores and small pores, the increases of the specific surface areas and pore volumes of the mesopores and large pores provided more spacious and advantageous channels for gas diffusion in the micropores and small pores. That is to say, the smaller the damage degree of the coal dust was (e.g., the greater the firmness coefficient), the longer the paths of the gas diffusion in the micropores and small pores would be and in turn the greater the 


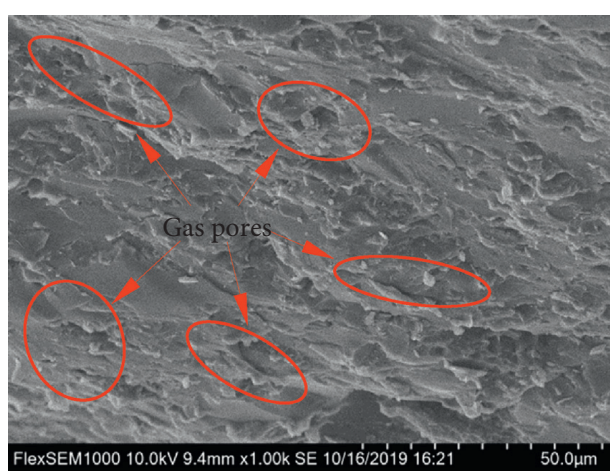

(a)

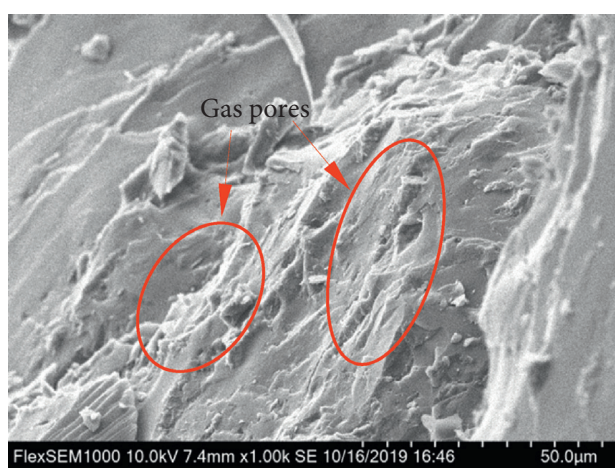

(c)

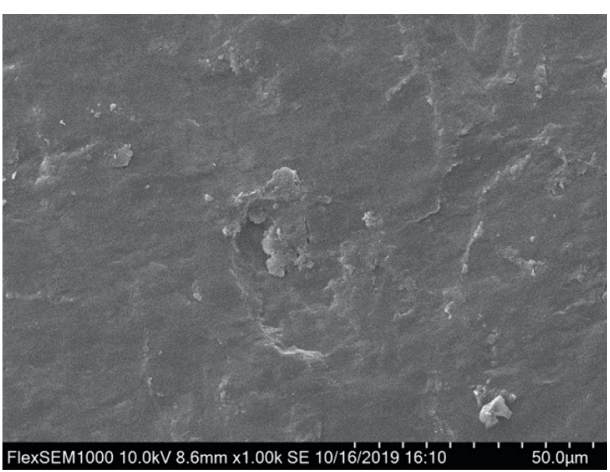

(b)

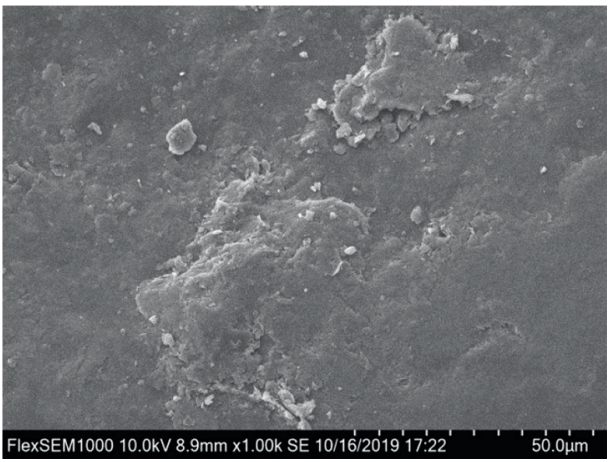

(d)

Figure 9: Microscanning results of the soft coal and hard coal. (a) No. 6 soft coal. (b) No. 6 hard coal. (c) No. 11 soft coal. (d) No. 11 hard coal.

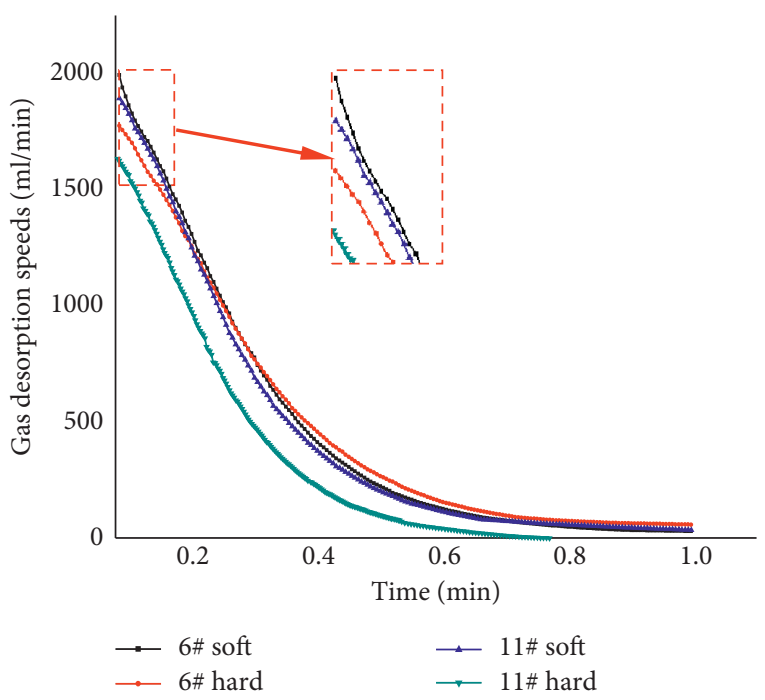

(a)

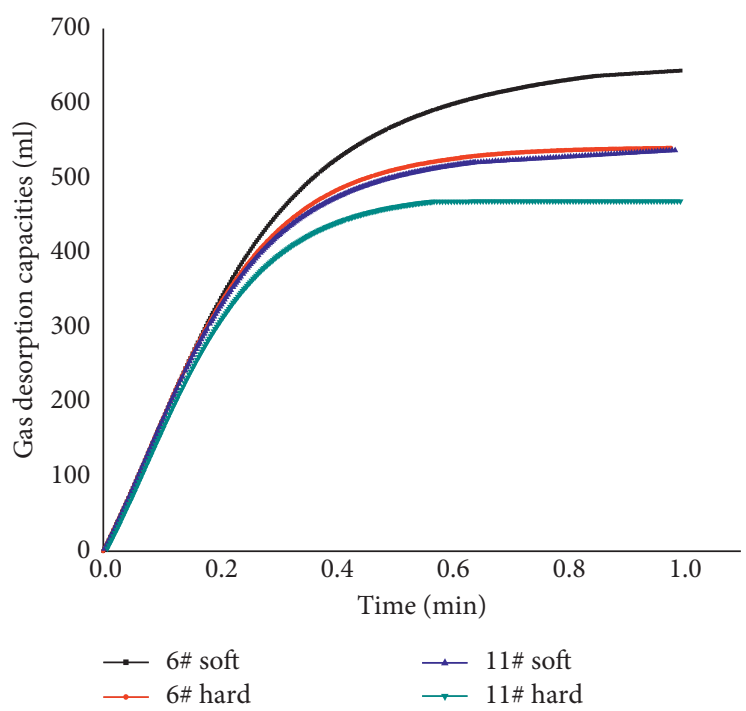

(b)

Figure 10: Gas desorption laws of the soft coal and hard coal. (a) Gas desorption speeds of the soft coal and hard coal. (b) Gas desorption capacities of the soft coal and hard coal.

resistance would be. Therefore, the increases in the damage degrees were equivalent to widening the channels for gas desorption in the micropores and small pores, which subsequently shortened the paths of gas diffusion and reduced the resistance of gas diffusion. This resulted in increases in the initial velocity of the gas released in the micropores and small pores. The mesopores of the soft coal were observed to be much larger than those of the hard coal. It was found that when the gas stored in the mesopores was desorbed, it did not need to directly 
TABLE 2: Gas desorption parameters of the soft coal and hard coal in the different coal seams.

\begin{tabular}{|c|c|c|c|c|}
\hline \multirow{2}{*}{ Gas desorption parameters } & \multicolumn{4}{|c|}{ Soft coal and hard coal bodies of the different coal seams } \\
\hline & No. 6 soft & No. 6 hard & No. 11 soft & No. 11 hard \\
\hline Initial speed of the gas desorption $(\mathrm{ml} / \mathrm{min})$ & 1993.26 & 1775.02 & 1924.53 & 1695.36 \\
\hline Gas desorption $(\mathrm{ml})$ & 643.45 & 539.74 & 630.98 & 532.02 \\
\hline
\end{tabular}

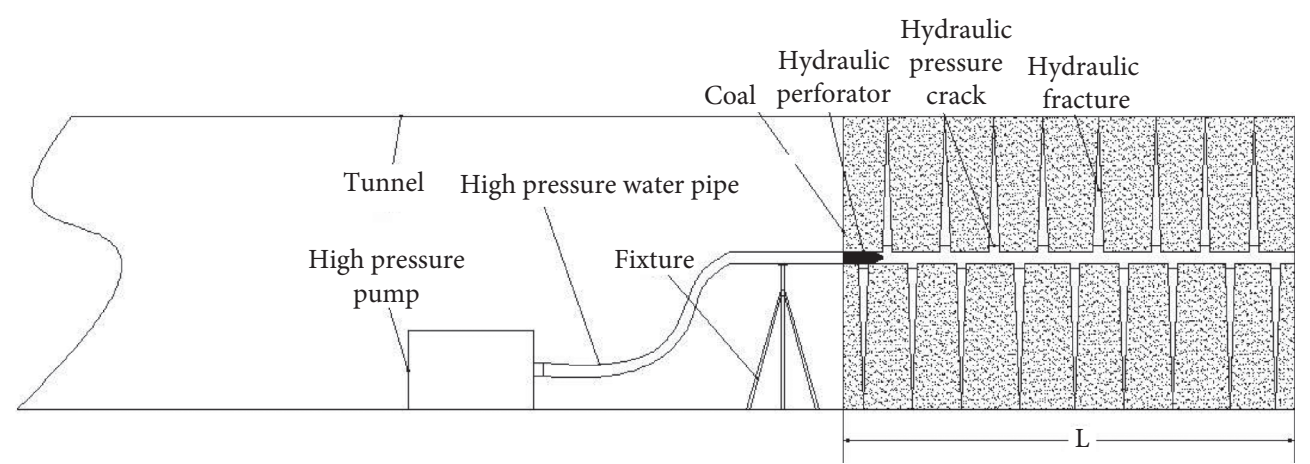

FIGURE 11: Schematic diagram of hydraulic perforation-hydraulic fracturing-gas drainage.

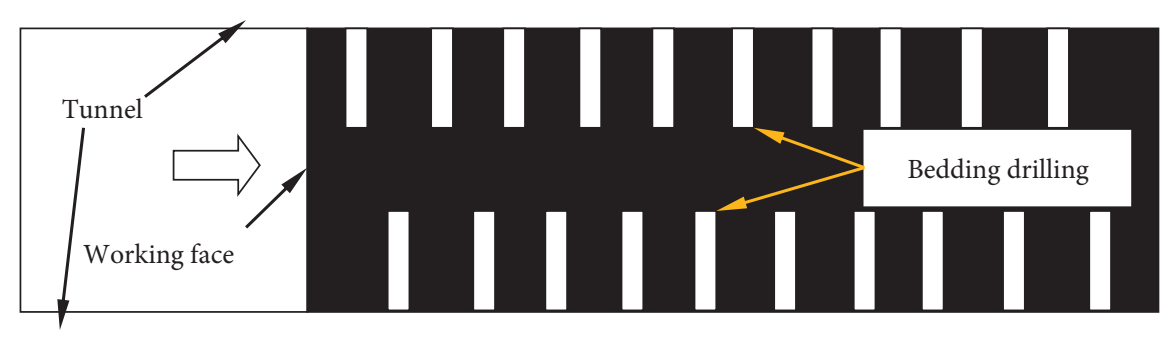

FIGURE 12: Gas drainage diagram of coal seam in working face.

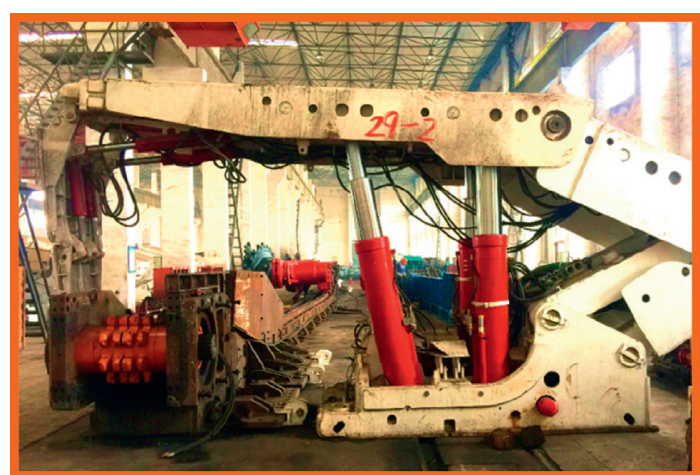

FIGURE 13: "Rigid support + flexible metal mesh" new rigid flexible composite active support system.

diffuse to the large pores or coal surfaces through the micropores or small pores. This had resulted in the initial velocity of the mesopore gas diffusion of the soft coal to be much faster than that of the hard coal. It was concluded in this study that this was the basic reason why the gas diffusion coefficient of the soft coal was larger than that of the hard coal. Therefore, the differences in the gas diffusion paths stored in different pores and locations could be considered as the reason why the gas diffusion coefficient of the coal particles had changed with time.

\section{Engineering Case}

According to the above research results, the combined mode of hydraulic perforation-hydraulic fracturing-gas drainage was adopted in the tunneling process of Xieqiao coal mine to preextract the gas in the coal body during the tunneling process, as shown in Figure 11. Before mining the coal seam in the working face, the bottom plate was used to dig the gas predrainage roadway to extract part of the gas in the coal seam. Before mining in the working face, the gas in the coal seam was extracted by drilling along the seam, as shown in Figure 12.

Due to the fact that the soft coal body has the problems of soft crushing and being easy to slice, we designed and adopted a new type of rigid flexible composite active support system of "rigid support + flexible metal net," which solved the problem of easy slicing of soft coal body in the coal seam and effectively prevented the sudden gas emission caused by the slice of coal wall, as shown in Figure 13. The effect is very good.

\section{Conclusions}

In the current research study, the differences in the characteristics of gas diffusion between soft coal and hard coal were examined from macroaspects, mesoaspects, and microaspects. The basic mechanism of the gas diffusion differences between the soft coal and hard coal was revealed and verified by the 
results of this study's gas desorption experiments. Through the above analysis and research results for soft coal and hard coal, there are important guiding significance and promotion value for gas regional control in the field construction process of working face. The following conclusions were obtained:

(1) In view of the special situation of gas emission in coal mines, this paper makes an in-depth study on the nature of abnormal gas emission law of soft coal and hard coal from macroaspects, mesoaspects, and microaspects. The mechanism of gas emission difference between soft coal and hard coal is revealed, which provides basis for the prevention and control of coal seam gas disaster under similar conditions, and has important significance.

(2) In the macroaspects and mesostructures of the soft coal, the particles were observed to be flakey with fingernail-like shapes, and there were generally no complete blocks. However, the hard coal was mainly composed of complete block structures. In addition, the proportion of coal particles sized below the particle size limit $(6 \mathrm{~mm})$ of the soft coal was much higher than that of the hard coal.

(3) The pores and fissures of the soft coal were found to be more developed than those of the hard coal. The BET and BJH specific surface areas of the soft coal were found to be more than twice those of the hard coal. Furthermore, the pore specific surface area increments and pore volume increments of the soft coal particles greater than $100 \mathrm{~nm}$ were found to be more than twice those of the hard coal. Therefore, the gas adsorption and diffusion migration conditions of the soft coal were superior to those of the hard coal.

(4) The experimental results of the soft coal and hard coal gas desorption showed that the gas desorption speeds, gas desorption capacities, initial gas desorption speeds, and other parameters were significantly higher for the soft coal than for the hard coal. Therefore, it was concluded that the soft coal was more likely to cause gas outbursts and transfinite accidents in a project site.

(5) A combined method of hydraulic perforation-hydraulic fracturing-gas extraction was put forward to extract the gas in the process of roadway excavation. The gas in the working face is extracted by drilling along the layer. According to the problems of soft coal, such as being soft and broken and being easy to slice, we designed a new type of rigid flexible composite active support system of "rigid support + flexible metal net," which solved the problem easy slicing of soft coal in the coal seam and effectively prevented the coal wall slice from causing the gas to gush out suddenly. The effect is very good.

\section{Data Availability}

The data used to support the findings of this study are included within the article.

\section{Conflicts of Interest}

The author declares that there are no conflicts of interest regarding the publication of this paper.

\section{Acknowledgments}

This research was funded by the Natural Science Foundation of Anhui Province (nos. 1908085QE226, 908085QE186, and 1908085QE184), Natural Science Foundation of the Anhui Higher Education Institutions (KJ2018A0077), the National Natural Science Foundation of China (51874006), National Key R\&D Program of China (no. 2017YFC0804202), and Science Research Fund for young teachers of Anhui University of Technology (QN2019119).

\section{References}

[1] Q. Xu and $\mathrm{K} . \mathrm{Xu}$, "Mine safety assessment using gray relational analysis and bow tie model," Plos One, vol. 13, no. 3, Article ID e0193576, 2018.

[2] Y. Yuan, Z. Chen, X. Zhang, and Z. Wang, "Intermediate coal pillar instability and permeability evolution in extremely thin protective seam by auger mining," Arabian Journal of Geosciences, vol. 12, no. 10, 2019.

[3] Q. Sun, J. Zhang, Q. Zhang, W. Yin, and D. Germain, “A protective seam with nearly whole rock mining technology for controlling coal and gas outburst hazards: a case study," Natural Hazards, vol. 84, 2016.

[4] W. Zhao, Y. Cheng, P. Guo, K. Jin, and H. Wang, "An analysis of the gas-solid plug flow formation: new insights into the coal failure process during coal and gas outbursts," Powder Technology, vol. 305, pp. 39-47, 2016.

[5] A. T. Zhou, K. Wang, T. A. Kiryaeva, and V. N. Oparin, "Regularities of two-phase gas flow under coal and gas outbursts in mines," Journal of Mining Science, vol. 53, no. 3, pp. 533-543, 2017.

[6] L. Cheng, "A sequential approach for integrated coal and gas mining of closely-spaced outburst coal seams: results from a case study including mine safety improvements and greenhouse gas reductions," Energies, vol. 11, p. 11, 2018.

[7] A. Zhou and W. Kai, "A new gas extraction technique for high-gas multi-seam mining: a case study in Yangquan Coalfield, China," Environmental Earth Sciences, vol. 77, p. 150, 2018.

[8] G. Lu, C. Wei, J. Wang, J. Zhang, and L. Soh Tamehe, “The variation of surface free energy in the process of methane adsorption in the nanopores of tectonically deformed coals: a case study of middle-rank tectonically deformed coals in the huaibei coalfield," Energy \& Fuels, vol. 77, 2019.

[9] X. Zhang, P. G. Ranjith, and M. S. A. Perera, "Gas transportation and enhanced coalbed methane recovery processes in deep coal seams: a review," Energy \& Fuels, vol. 30, p. 11, 2016.

[10] H. Zhang, Y. Cheng, L. Yuan, L. Wang, and Z. Pan, "Hydraulic flushing in soft coal sublayer: gas extraction enhancement mechanism and field application," Energy Science and Engineering, vol. 7, no. 1, 2019.

[11] M. Ya and L. Zhiping, "Experimental comparisons of gas adsorption, sorption induced strain, diffusivity and permeability for low and high rank coals," Fuel, vol. 234, pp. 914923, 2018. 
[12] Q. Tu, Y. Cheng, P. Guo, J. Jiang, L. Wang, and R. Zhang, "Experimental study of coal and gas outbursts related to gas-enriched areas," Rock Mechanics \& Rock Engineering, vol. 49, no. 9, pp. 3769-3781, 2018.

[13] K. Jin, Y. Cheng, T. Ren, W. Zhao, Q. Tu, and J. Dong, "Experimental investigation on the formation and transport mechanism of outburst coal-gas flow: implications for the role of gas desorption in the development stage of outburst," International Journal of Coal Geology, vol. 194, pp. 45-58, 2018.

[14] Q. Liu, E. Wang, X. Kong, Q. Li, S. Hu, and D. Li, "Numerical simulation on the coupling law of stress and gas pressure in the uncovering tectonic coal by cross-cut," International Journal of Rock Mechanics and Mining Sciences, vol. 103, pp. 33-42, 2018.

[15] B. Lin, Q. Zou, Y. Liang, J. Xie, and H. Yang, "Response characteristics of coal subjected to coupling static and waterjet impact loads," International Journal of Rock Mechanics and Mining Sciences, vol. 103, pp. 155-167, 2018.

[16] Z. Wang, J. Pan, Q. Hou, B. Yu, M. Li, and Q. Niu, “Anisotropic characteristics of low-rank coal fractures in the Fukang mining area, China," Fuel, vol. 211, pp. 182-193, 2018.

[17] P. Guo, Y. Cheng, K. Jin, W. Li, Q. Tu, and H. Liu, "Impact of effective stress and matrix deformation on the coal fracture permeability," Transport in Porous Media, vol. 103, no. 1, pp. 99-115, 2017.

[18] L. Zhang, Z. Ye, J. Tang, and D. Hao, "Comparative experiment study on nitrogen injection and free desorption of methane-rich bituminous coal under triaxial loading," Archives of Mining Sciences, vol. 62, no. 4, pp. 911-928, 2017.

[19] Q. Zhang, Y. Cheng, Q. Liu et al., "Investigation of the formation mechanism of coal spallation through the crosscoupling relations of multiple physical processes," International Journal of Rock Mechanics and Mining Sciences, vol. 105, pp. 133-144, 2018.

[20] M.-Y. Jiang, Y.-P. Cheng, J.-C. Wang, H.-R. Li, and N. Wang, "Experimental investigation on the mechanical characteristics of gas-bearing coal considering the impact of moisture," Arabian Journal of Geosciences, vol. 12, no. 18, 2019.

[21] G. Haijun, Y. Liang, C. Yuanping et al., "Effect of moisture on the desorption and unsteady-state diffusion properties of gas in low-rank coal," Journal of Natural Gas Science and Engineering, vol. 57, pp. 45-51, 2018.

[22] B. Hu, Y. Cheng, Z. Wang, X. He, and L. Wang, "Effect of pulverization on the microporous and ultramicroporous structures of coal using low-pressure $\mathrm{co}_{2}$ adsorption," Energy \& Fuels, vol. 2019, 2019.

[23] W. Szott, A. Gołąbek, K. Sowiżdżał, and P. Łętkowski, "Numerical studies of improved methane drainage technologies by stimulating coal seams in multi-seam mining layouts," International Journal of Rock Mechanics and Mining Sciences, vol. 108, pp. 157-168, 2018.

[24] G. Słota-Valim, Z. Yin, L. Wang, Z. Hu, and C. Zhu, "Effects of gas pressure on the failure characteristics of coal," Rock Mechanics and Rock Engineering, vol. 50, no. 7, pp. 1711-1723, 2017.

[25] Z. Yin, W. Chen, H. Hao et al., "Dynamic compressive test of gas-containing coal using a modified split Hopkinson pressure bar system," Rock Mechanics and Rock Engineering, vol. 53, no. 2, pp. 815-829, 2020. 